\title{
PALESTRA
}

\section{ACTUALIDAD Y PROSPECTIVA DEL DISEÑO EN AMÉRICA LATINA}

\section{María Verónica Barzola}

Facultad de Diseño y Comunicación

Universidad de Palermo (Argentina)

mbarzo1@palermo.edu

\begin{abstract}
La ponencia presentada en el marco del P\&D 2016, muestra los resultados de la "Encuesta de percepciones sobre del Diseño Latino", investigación internacional colaborativa realizada por la Facultad de Diseño y Comunicación de la Universidad de Palermo (Argentina). El proyecto tuvo como objetivo principal indagar las diferentes visiones de la comunidad latinoamericana sobre la enseñanza, el desarrollo profesional, la imagen actual de la disciplina y los diez grandes desafíos del diseño para la próxima década.
\end{abstract}

Palabras clave: encuesta, diseño latino, pedagogía del diseño, profesionalización.

María Verónica Barzola es Licenciada en Relaciones Públicas (Universidad de Palermo, 2005), Master en Relaciones Internacionales (Università di Bologna, 2007) y Doctoranda en Ciencias Políticas y Relaciones Internacionales (Universidad Complutense de Madrid). Forma parte del Cuerpo Académico de la Maestría en Gestión del Diseño. Es directora de la línea de investigación Presente y Futuro del Diseño Latino. 
Encuesta de percepciones sobre del Diseño Latino es una investigación internacional colaborativa realizada por la Facultad de Diseño y Comunicación de la Universidad de Palermo (Argentina) que indaga en las diferentes visiones de la comunidad latinoamericana sobre la enseñanza, el desarrollo profesional, la imagen actual de la disciplina y los diez grandes desafíos del diseño para la próxima década.

El objetivo principal del proyecto fue concretar un acercamiento a las opiniones de actores del amplio y extenso mundo del arte, la cultura y las comunicaciones de América Latina - como académicos, emprendedores, artistas, policy makers, estudiantes, empresarios, etc.- sobre la actualidad y el devenir de la disciplina. Para ello, entre abril y mayo, se puso en marca una encuesta online que obtuvo casi 3000 respuestas.

El primer eje abordó las percepciones sobre la enseñanza y la pedagogía del diseño en el continente, tanto en lo que respecta a contenidos, currícula, interrelación con la sociedad y aporte docente a la tarea. Cabe destacar que el 47,89\% de los encuestados remarcó que los contenidos y la currícula de las carreras y cursos de diseño preparan a los egresados para enfrentar los pedidos del mercado. A pesar de esto, más de la mitad manifestó una opinión contraria o no definida, probablemente porque "el mercado cambia más rápidamente que la formación", tal como sostiene Roland, Emprendedor Creativo brasilero del Área Diseño de Productos y Objetos que contestó la encuesta.

Un 53.53\% confirmó que las instituciones educativas poseen la suficiente capacidad de respuesta frente a las demandas de cada una de las regiones y casi en la misma proporción concordó que el plantel docente está actualizado y acorde a los desafíos que la disciplina requiere.

Por otra parte, casi la mitad de los encuestados manifestó que tiene dudas si la educación del diseño está actualizada, o sabe directamente que no lo está, en función de las tendencias tecnológicas. Esto abre nuevamente el debate sobre si la pedagogía del diseño debe dedicarse a transmitir formas de pensar y de resolver problemas en vez de abocarse a enseñar herramientas tecnológicas que se desactualizan rápidamente, o viceversa.

El segundo eje, Percepciones sobre el perfil y el desarrollo profesional, despertó una alerta acerca de la valoración de los diseñadores en el mercado latinoamericano. El $47.97 \%$ de los encuestados sostuvo que el rol profesional del diseñador no está debidamente jerarquizado en su país. En este sentido, Renato, un profesor argentino que respondió la encuesta aclara: "está mucho más valorado que hace años, pero todavía falta ocupar un mejor y más importante espacio en la sociedad". Carlos, emprendedor creativo venezolano, aclara que la problemática es una cuestión 
generacional: "aún hay una franja etaria que no ve lo importante de la profesión del diseño en las empresas de cualquier sector".

Sin embargo, y en contraposición a esto, el $81.95 \%$ de los encuestados aseveró que el mercado del diseño latinoamericano ha crecido en la última década, generando más oportunidades laborales y abriéndose nuevos nichos de interés. "Latinoamericana es un caldo de creativos. Somos una raza que se reinventa cada rato. Somos una mezcla de razas, de culturas y de dialectos, de habla hispana o portuguesa, pero con coloquios propios y una chispa única" sostiene Elluz, una diseñadora venezolana que participó de la encuesta.

Por otro lado, es interesante destacar que cuando se consultó acerca del aspiracional personal y la proyección profesional de los entrevistados a cinco años, se corroboró que más de la mitad de los encuestados se imagina trabajando por su cuenta generando productos de diseño u ofreciendo el diseño como servicio (llevando adelante un emprendimiento creativo - un 33,5\% - o liderando su propia agencia de diseño - un $16.80 \%$ ). De los restantes, el $17.20 \%$ se proyecta haciendo un posgrado; el $10.40 \%$, trabajando en relación de dependencia; el $8.80 \%$, terminando la carrera de grado; el $7.50 \%$, desempeñándose en la docencia universitaria; y un $5.80 \%$ se proyecta realizando otras actividades (como gestión de galerías/curaduría, desarrollo investigaciones interdisciplinarias, organización de eventos, etc.).

Se indagó además sobre la imagen actual del diseño, tercer eje, y en concreto se consultó sobre la cercanía de la disciplina con otras profesiones o áreas. En este sentido, casi la mitad de los encuestados (44.88\%) respondió que el diseño se encuentra más cercano al campo de las comunicaciones que a otras áreas disciplinares, mientras que el $27.17 \%$ señaló la vinculación con los negocios y el $22.47 \%$ al arte. Un $5.48 \%$ sostuvo que el diseño no se halla cercano a ninguna de las anteriores.

Como último eje de análisis se pidió a los encuestados que identifiquen los grandes desafíos del diseño latino para la próxima década. Y los diez más nombrados fueron los siguientes: profesionalizar la disciplina, priorizar la creatividad antes que la rentabilidad, valorar al diseñador como autor y gestor, desarrollar vínculos institucionales, posicionar el diseño latinoamericano a nivel global, jerarquizar al diseño sustentable, desarrollar el diseño autóctono, aumentar la valoración profesional del diseñador, desarrollar el diseño social e impulsar redes latinoamericanas.

La encuesta de percepciones se realizó en el marco de la Línea de Investigación Presente y Futuro del Diseño Latino, del programa de Investigación y Desarrollo de la Facultad de Diseño y Comunicación, y con la activa participación de los Embajadores del Diseño Latino (más de 120 académicos y profesionales destacados en el diseño en 
América Latina). Ellos permitieron que la investigación tuviese carácter internacional y colaborativo, actuando como nodos difusores y garantizando la representación local en cada uno de los países. Actualmente los resultados han sido entregados al Comité de Embajadores, que se encuentra elaborando las conclusiones que serán presentadas en formato de papers académicos en la publicación Cuadernos del Centro de Estudios de la Universidad de Palermo. 